\title{
3 Research Square

\section{The Perceptions of the Working Environment of Anaesthesiologists Migrating From the Public to the Private Sector in a Developing Country: An Exploratory, Qualitative Study}

\author{
Matthew Graeme Kolling ( $\sim$ mattygk@gmail.com ) \\ University of the Witwatersrand https://orcid.org/0000-0002-5098-0452 \\ Juan Scribante \\ University of the Witwatersrand \\ Helen Perrie \\ University of the Witwatersrand \\ Lionel Green-Thompson \\ University of Cape Town Faculty of Health Sciences
}

Research

Keywords: anaesthesiology, working environment, migration, staff retention

Posted Date: July 23rd, 2020

DOl: https://doi.org/10.21203/rs.3.rs-46122/v1

License: (c) (i) This work is licensed under a Creative Commons Attribution 4.0 International License.

Read Full License 


\section{Abstract \\ Background}

There is a significant disparity in the distribution of medical practitioners within the public and private healthcare sector of South Africa. This study explores the perceptions of anaesthesiologists of their working environment in the public sector following their migration into private practice. Their reasons for leaving are largely unknown.

\section{Methods}

Rich pictures were applied in an exploratory, qualitative research design using Checkland's Soft Systems Methodology. Anaesthesiologists (specialist anaesthetists), who left the Department of Anaesthesiology at the University of the Witwatersrand between 2014 - 2017 and were working in the private sector in the Johannesburg Metropole were invited to a workshop. Participants were asked to draw a rich picture to illustrate their perceptions of the working environment in the Department and to then draw a picture to depict the ideal anaesthesiology working environment in the Department. Explanations of their pictures were audio recorded and deductive thematic analysis was used to analyse the data, guided by Herzberg's Motivation- Hygiene Theory.

\section{Results}

The rich data from this study suggests job dissatisfaction and a lack of satisfaction in the Department due to poor hygiene and motivator factors such as poor working conditions, challenging workplace relationships, inflexibility with work-life balance and a lack of accountability. These factors are some of the important reasons for migration of anaesthesiologists from public to private practice.

\section{Conclusion}

This study demonstrates the complexity of interactions between individuals working together in systems which are often in tension and are sensitive to multiple dynamic influences. These systems are contextspecific but need to recognise the factors which may ultimately impact quality health service delivery and education.

\section{Background}

Human resources of health, which are central to the delivery of healthcare services, remain a challenge in South Africa (SA). The SA 2030 Human Resources for Health Strategy acknowledges the current inequities between the public and private healthcare workforce. In addition, the strategy seeks to improve the working environment for those working in the public sector (1). This complex healthcare system 
affects healthcare workers with multiple dynamic influences, causing satisfaction and dissatisfaction in the working environment. Job satisfaction leads to a desirable work ethic and reduces the likelihood of employee migration (2). In 1959, Frederick Herzberg proposed the Motivation-Hygiene Theory to describe the factors that motivate and satisfy employees in the working environment (3). The issue of employee turnover and retention has been identified by human resource professionals as an increasingly important management challenge in recent years (4). Employees play a significant role in the sustainability of an organisation (5) and poor staff retention is often a sign of deeper, underlying issues (6). However, employee migration is also fundamental to the growth and relevance of an organisation (7) and it is important to find a balance between both functional and dysfunctional turnover (8).

The South African healthcare system is characterised by a shortage and a maldistribution of healthcare workers (9). The Health Market Inquiry (10) reported in 2019 that "access to medical practitioners in the private sector $(1.75$ per 1000$)$ is in stark contrast to access in the public sector (0.3 per 1000$)$ " of South Africa. The number of medical practitioners in the private sector has increased annually (10). The public healthcare sector has fewer healthcare facilities but serves the majority (approximately 83\%) of the South African population (10), with the greatest burden of disease and HIV prevalence. Training of South African doctors takes place in the public sector and the distribution of practitioners means that doctors are moving away from areas where their service is most required (11). The poor retention of healthcare workers in the rural areas has been attributed to limitations in career advancement, poor working environment, lower salary and a high workload (12). Farham (13) feels that retention schemes and incentives to work in the rural areas of South Africa were not enough to make up for the poor working conditions and deterioration of public health services.

Health systems, such as the public sector anaesthesia environment, represent complex systems sensitive to multiple dynamic influences (14). This study explores the perceptions of anaesthesiologists of their working environment in the public sector following their migration into private practice and also examines their perceptions of the ideal working environment.

\section{Methods}

This study applied rich pictures in an exploratory, qualitative research design. Checkland's Soft Systems Methodology (15) supports the idea "that a picture paints a thousand words" (16). Drawing pictures may be better than prose as a very effective way of depicting complex situations where there are multiple interacting relationships (15). The Human Research Ethics Committee (Medical) at Wits (M181050) and other relevant authorities approved this study.

The study population consisted of anaesthesiologists (specialist anaesthetists), who left the Department of Anaesthesiology (the Department) at Wits between 2014 - 2017 and were working in the private sector in the Johannesburg Metropole. Purposive sampling was used in this study and eligible anaesthesiologists were invited to a workshop held at a neutral venue after working hours. This was facilitated by two authors (MK and JS). 
Participants gave written consent for participation and recording of the workshop. Demographic data (sex, marital status, years of anaesthesiologist experience and departure date from the Department) were collected. The study and the methodology of rich pictures was introduced. Participants were then divided into two groups and each group was asked to draw a picture to illustrate their perceptions of the working environment in the Department. Once the pictures were drawn, each group was asked to explain what they had drawn. The groups were then asked to draw a picture to depict the ideal anaesthesiology working environment in the Department and explain their pictures once again. The participants' explanations of their pictures were audio recorded using two mobile phones. Descriptive and reflective field notes were taken during and after the workshop by author (MK).

The author (MK) transcribed the audio recordings verbatim, which were checked by the other authors for accuracy. Deductive thematic analysis (17) was applied, guided by Herzberg's Motivation-Hygiene Theory (3). The sequence of events of data collection and analysis are displayed in Figure 1.

The authors meticulously analysed the recorded explanations and discussions of the pictures, thereby ensuring that the trustworthiness of the study met the criteria of credibility, dependability, confirmability, transferability and authenticity. Further in this report participants are referred to by the group that they were in and a letter within a group system.

\section{Results}

Twelve enthusiastic participants (Table 1) attended a three and half hour workshop on the evening on 13 March 2019. They were divided into two groups. The rich data obtained reflected the participants' commitment and interest in academic anaesthesiology.

Table 1 Demographic data of the participants

\begin{tabular}{|c|c|c|c|}
\hline \multicolumn{2}{|l|}{ Workshop date } & \multicolumn{2}{|c|}{13 March 2019} \\
\hline \multicolumn{2}{|l|}{ Participants } & \multicolumn{2}{|c|}{ Number of participants } \\
\hline & & Group 1 & Group 2 \\
\hline \multirow[b]{2}{*}{ Sex } & Female & 3 & 2 \\
\hline & Male & 4 & 3 \\
\hline \multirow[b]{2}{*}{ Marital status } & Married & 7 & 3 \\
\hline & $\begin{array}{l}\text { Not } \\
\text { Married }\end{array}$ & 0 & 2 \\
\hline \multirow{3}{*}{$\begin{array}{l}\text { Years of experience as a } \\
\text { specialist }\end{array}$} & $<2$ years & 1 & 2 \\
\hline & 2.5 years & 4 & 2 \\
\hline & $>5$ years & 2 & 1 \\
\hline \multirow{4}{*}{$\begin{array}{l}\text { Departure date from the } \\
\text { Department }\end{array}$} & 2014 & 0 & 0 \\
\hline & 2015 & 2 & 2 \\
\hline & 2016 & 2 & 1 \\
\hline & 2017 & 3 & 2 \\
\hline
\end{tabular}


The participants named their first two pictures. "The days of our lives" (a soap opera analogy) was chosen by the first group to represent their experience of chaos and drama at the time of their migration. This unpleasant working environment was characterized by poor interpersonal and interdepartmental relationships. The second group titled their picture "War and Peace/Going nowhere slowly". Participants described a sense of enormous effort resulting in the feeling of defeat of going nowhere slowly.

The ideal working environments, illustrated in pictures titled "Paradise Road" and "Peace in our time" by the groups respectively, reflected efficient and effective operating room systems in which mutual respect allowed individuals to feel valued as team members.

Herzberg (3) identified two broad categories, (hygiene factors and motivator factors), which lead to dissatisfaction and satisfaction within the working environment respectively. Herzberg's MotivationHygiene Theory is represented in Figure 2.

Permission obtained and adapted from Tools Hero (18)

\section{Hygiene factors}

The working conditions were significantly limited by a lack of resources and participants found it demotivating to work in this environment. "[It] just felt that there weren't enough facilities to deal with whatever we had to deal with" (2F). A participant expressed her frustration, "The time wasting, the lack of resources, linen, equipment, staff, beds, having to push patients to the wards, bring them down for a procedure because you couldn't find a porter" $(2 \mathrm{H})$. Replacing disposables (such as gloves and syringes) was challenging because they did not arrive on time, despite being ordered well in advance. Participants felt that the lack of general upkeep and poor hygiene within the public healthcare sector made working conditions unpleasant. "Germs... I really feel it's very dirty" (2F).

Participants experienced a heavy workload and long hours. "The patients in [the public sector] were a lot sicker, a lot more stressful" $(2 \mathrm{H})$. Having to study for examinations and work long hours with a heavy workload made one participant feel "...quite fragile... sleep deprived and tired most of the time" (2F). Participants agreed that anaesthetists do not deal with stress appropriately and often participate in "risky behaviour" (2F), using substances such as alcohol as an outlet to destress.

Participants expressed their dissatisfaction with certain Departmental policies and felt that administrative practices could be improved. They mentioned being "treated like high school children" (1B), often having to stay, despite working hard and finishing their theatre list early, needing to report when they arrived at work and when they left. The Department of Human Resources was described as a "big pain" (1B). There was a general reflection of administrative and logistic processes of leaving being "humiliating and irritating that you sit in a queue for an hour to leave work because they want to search your car... There's like no trust" (1A). 
After qualifying as a specialist, participants initially felt inspired and motivated to make improvements to "the system" (2F), which referred to the day to day functioning of the Department. However, they felt less empowered to make a difference over time, with the realisation that the system was not conducive to change mostly because of "red tape" $(1 \mathrm{~A})$ or bureaucracy. This was illustrated with bold red tape with the words "NO HOPE" written across it. A powerful statement was made by a participant, who drew a bathtub to illustrate her point. "You put so much effort [into the system] and it all just goes out. You never actually filling up the bathtub with water. It's just like filling up a bath with no plug" (2J). One participant drew handcuffs, demonstrating that he "felt very constrained by a lot of things, [such as] the environment, red tape, bureaucracy... constrained by the whole system..." (2F).

There was very little emphasis placed on salaries and benefits, suggesting their relative insignificance as a cause of dissatisfaction leading to their migration. A participant mentioned, towards the end of the workshop, "we earn decent salaries as registrars... we didn't think that being salaried more was an issue" $(2 \mathrm{~F})$.

Clinical supervision was perceived as better than in other departments. A dichotomy with respect to supervision and support within the Department was presented. The sense of support when one was struggling was countered by "conflicting opinions from consultants..." (2F) and having little responsibility as a junior often meant that you "didn't learn from experience [because]... most of the decisions were made for you by seniors" (2F). This was termed "anaesthesia by commission" (2F) by a participant. As a senior registrar, having to supervise many junior anaesthetists was also very stressful, especially when you had sick patients.

Support during critical events also varied depending on a participant's position of seniority at the time of the event. It was acknowledged that registrars were protected and supported in the Department. However, consultants carried a lot more responsibility and sometimes people are "... blamed for it in a way that's harmful to their confidence... " $(1 \mathrm{~A})$, rather than experiencing a supportive environment, with appropriate debriefing and a chance to learn from the critical event.

Participants experienced an unhealthy hierarchy. There was a sense that "you just need to know where your place is and to keep your mouth shut" (1B). As a consequence, participants felt intimidated by some seniors. Participants reflected on the pressure of performance: "You needed to prove yourself... and show your worth and after this, interaction was limited to an occasional greeting" (2F).

Participants generally did not approve of the "protected employment" $(1 \mathrm{~A})$ and job security within the Department. Participants felt there was a lack of accountability due to the absence of regular evaluation of the performance of colleagues. This meant that some anaesthetists were "coddled and sheltered" (2F) and "the system just made it possible for them to go through" (2F).

The working relationships amongst theatre staff was a prominent theme that generated intense discussion. Obstacles existed within the Department with "politics" and "factions" $(2 \mathrm{H})$ influencing working conditions unfavourably. Hard-working individuals did most of the work, literally pulling the 
weight of others on a pulley system, while others are sleeping close by (as depicted by an illustration). Consultants described some registrars as "rotten apples" (1D) because of their poor work ethic.

An image emerged of two people pulling the emergency operation theatre list in opposing directions depicting the struggle between surgeons and anaesthetists on a daily basis. Participants reported poor relations with surgeons based on communication and perceived lack of competence. "We are not blameless" (1G), as anaesthetists can sometimes be obstructive and unprofessional. Some participants expressed that the public sector did not allow them to select a surgeon with a matched work ethic to work with, as they do in the private sector. Participants agreed that anaesthetists should behave in a professional manner and "... if we actually listen to [surgeons] and have better relationships with them, the theatre experience would be better, for everyone" $(2 \mathrm{H})$.

The relationships with patients made a lasting impression on participants. They sympathised with patients who were not always prepared for theatre and were sometimes "in such a state that they [were] actually past the point of resuscitation" (1A). A participant described her dissatisfaction with the way patients are treated in the public sector, "probably the biggest reason why I left was like there was no empathy for patients" (2J). Patients are often not counselled regarding their anaesthetic or surgical choices. They are not always appropriately informed for consent. Children are mostly unaccompanied by parents and families are seldom included in patient care. However, "The patients [in the public sector] are really appreciative" (2F), which made the work satisfying to one participant.

The balance between work and personal life was important to all participants and they felt that this was largely, not optimal. They described how they sometimes had to beg for leave and missed important family commitments because work was demanding and lacked flexibility. A participant drew a picture of his "wife crying", demonstrating that his marriage took quite a lot of strain at times. Taking sick leave sometimes meant that one was unintentionally punished upon return to work, being given extra work to make up for their absence. Maternity leave was however described as a positive aspect of the Department.

\section{Motivator factors}

Participants valued recognition for their good work ethic. However, they describe a lack of positive feedback or encouragement if cases did not go according to plan. Key performance indicators are nonexistent in the Department, which made it difficult for registrars and consultants to advance personally and demonstrate professional growth. The academic culture within the Department stimulates professional growth, but this is not always prioritised as anaesthetists are often working in theatre and unable to attend tutorials. The high service burden is prioritised over academic engagement. Registrars are often protected within the Department and do not have as much responsibility as consultants. Working in the Department meant that participants were presented with challenging cases, which contributed to professional growth and this job challenge led to satisfaction in the workplace. However, consultants complained of spending a lot of time "doing more portfolio [administrative] work than you do 
actual clinical work..." (1A). It was frustrating that anaesthesiologists spent most of their time doing work that does not directly relate to your training as an anaesthesiologist.

\section{An ideal working environment for the Department Hygiene factors}

The participants felt that working conditions would be a lot better if the hours were more reasonable and there were sufficient staff to manage the high patient load.

Anaesthesiologists would be less dissatisfied if there were no resource limitations and all equipment was functional. An ideal working environment would be one where we have "enough manpower, enough staff, having enough stock and equipment" (1A). Adequately staffed peripheral hospitals and an appropriate referral system would reduce the patient load on the tertiary hospitals, ultimately improve working conditions.

Departmental policies should value autonomy and flexibility for anaesthetists. Participants felt that they should be allowed to go home early if they worked hard and finished their list in a timely manner. They desired a Department where one has a choice regarding the lists that you do, the people you work with and the academics with which you are involved. Participants felt that there should be better structure to the registrar rotations, where you "have some seniority before you do certain stuff... [instead of being] plugged into where [you] are needed just to fill the gaps and deliver a service..." (2F). Departmental policies should focus on adequacy of training and professional growth, without automatic progression to the next rotation. Often registrars "complete" a neurovascular rotation, but do not necessarily receive the required training. Participants wished to be valued as a staff member, have designated, subsidised staffparking and not be searched after work. They were of the opinion that an efficient and friendly human resource team could assist with administrative issues that are not easily managed by anaesthetists. Participants felt that the ideal department requires managers in the right roles who are effective and willing to tackle problems head on. You need "people that can fix problems and not just cancel them or push them on the back burner" (2F). There should be appropriate and effective crisis support if a critical event occurs. This should be an opportunity to learn instead of an environment of blame and judgement. A debriefing should take place and a discussion of how to improve our practice when a similar event occurs. The ideal working environment should foster relationships based on teamwork and respect.

Having "good teamwork amongst the surgeons, anaesthetists and nurses... will make things move along more effectively" (1A) and more efficiently. Patient and family involvement were very important to participants who felt that we should create an environment of autonomy, where patients are better informed about their surgical procedures and anaesthetic options. Flexibility with aspects of your personal life was very important to participants. "Valuing of staff, valuing family time, valuing like what you guys have after work and it's not solely about work..." (1A). "Not having to beg people for leave or being able to have flexibility around that" (2F).

\section{Motivator factors}


Participants felt that being recognised for one's hard work was as important as being held to account for a substandard performance. "If you're strong and you do your job and you graft hard, you should get rewarded for that" $(2 \mathrm{~F})$. An annual review should be performed to ensure that registrars achieve their competencies rather than allowing "automatic progression" $(1 \mathrm{~A})$ to the next stage of their training. This gives individuals control over their professional achievements and advancement within the Department. There should also be designated times out of theatre for protected teaching, with an opportunity for tutorials and simulation training, despite the public sector being service delivery oriented.

Participants felt that there was a lack of accountability with limited consequence for detrimental actions in the public sector. "If staff are more accountable for their actions or performance, perhaps their work ethic would drastically improve, and the system will function more efficiently" (1G).

Participants desire a Department where you are able to focus on work that is of personal interest and have a choice regarding "what list you're on, where you work and how you want to split your time..." (2F).

\section{Discussion}

In Herzberg's theory (3) poor hygiene factors lead to dissatisfaction in contrast to motivator factors, which are the primary cause of satisfaction. Both satisfaction and dissatisfaction are discrete and described as being present or absent across a spectrum. If a hygiene factor were absent or poor, this would lead to dissatisfaction in the working environment and may negatively affect employee retention. The migration of healthcare workers is influenced by these factors and can result in maldistribution of human resources in a setting already characterised by severe shortage $(9,19)$. When an employee leaves an organisation, this can be disruptive to service delivery and finding a replacement can be costly (20).

Despite much criticism, over 60 years later, our study demonstrates the relevance and utility of Herzberg's Motivation-Hygiene Theory (3) in a contemporary working environment. Their recent departure from the Department by this representative group of anaesthesiologists and the rich data collected during the workshop provides useful and relevant insights into the perceptions of the working environment of anaesthesiologists in the public healthcare sector of Johannesburg, South Africa. Dissatisfaction and a lack of motivation contribute to migration of anaesthesiologists from public to private sector practice as is evident by the poor hygiene and motivator factors within the Department. It has been suggested that "push factors" are reported to have a far greater influence on an employee's decision to leave, than "pull factors" (21). In this study important "push factors" include: working conditions, relationships in the working environment, flexibility with respect to work and personal life balance and accountability.

The rich pictures drawn were aptly named by participants and the second pictures depicted contrasting themes to the first. The first pictures illustrated the unpredictable day-to-day battle facing anaesthetists in the theatre environment as suggested by the title: "War \& Peace". The perceptions of the working environment in the Department was characterised by resource constraints, poor infrastructure and a heavy stressful workload. These poor hygiene factors caused dissatisfaction and frustration among participants, who felt that they were not adequately equipped to perform their daily duties and worked in 
an environment that lacked flexibility with work-life balance. The relationship dynamics within theatre often created an unpleasant working environment, which was not conducive to work productivity. A supportive workplace has shown to reduce employee turnover among allied health professionals in Australia (22). Anaesthesiologists in Finland felt that lack of recognition, poor communication between colleagues, long working hours and organisational justice problems (related to work place fairness) all lead to dissatisfaction (23). The lack of accountability within the Department creates an environment of job security and protected employment. Participants felt that work ethic among staff would drastically improve if everyone was more accountable for how they conduct themselves in the working environment, rather than allowing automatic progression or promotion (24).

The second pictures were characterised by "Paradise" and "Peace" with theatre staff having common goals in an environment based on teamwork, communication and tolerance which improves efficiency, productivity and creates a more pleasant working environment for everyone (24). Relationships with patients focus on a more patient centred approach where anaesthetists display empathy, involving patients and family to a greater extent. The ideal department takes your personal life into account and offers more flexibility regarding your work-life balance. The issue of "role ambiguity" highlights the difference between what we feel the job entails with what is expected of us within the organisation (5). The participants felt that you should be able to focus on their interests, whether it be research, clinical work or administrative work and that you should be able to decide what lists you do or who you work with. The participants' role in the Department was not always clear and they mentioned doing non-clinical work, unrelated to their training as anaesthesiologists (5). Making employee responsibilities visible, by valuing employee contribution and giving constructive feedback will allow employees to feel the sense of achievement and acknowledgement that they desire (25).

Addressing poor hygiene factors and increasing motivator factors lead to employees being highly motivated and satisfied, with minimal complaints in the working environment. Identifying these factors results in a desirable work ethic and reduces migration from public to private sector practice. Hygiene factors are usually easier to address and should therefore be optimised first because this tends to result in an increase in motivator factors.

While it is easy to complain about current issues within the Department, it was recognised that improving working environment conditions would require a lot more thought, effort and time. Part of the solution to South Africa's crisis in human rights is addressing the health workforce inequities, the limited available resources and valuing health worker recognition and development (1). The wellbeing of healthcare workers is about creating a working environment characterised by a nurturing, enabling and supportive culture, which has a positive effect on morale and mental health (1).

\section{Conclusion}

This study demonstrates the complexity of interactions between individuals working together in systems which are often in tension. These systems need to acknowledge the hygiene and motivation factors 
which may ultimately impact quality health service delivery and education. However, the complexity of the Department is context-specific and cannot be applied to all settings. The results of this study demonstrate poor hygiene factors and inadequate motivation factors in the Department, while pointing out the relevance of Herzberg's theory in today's setting.

The reasons given by participants for the migration from public to private practice needs to be further explored in order to facilitate retention of anaesthesiologists in the public sector.

\section{List Of Abbreviations}

SA: South Africa

Wits: The University of the Witwatersrand

\section{Declarations}

\section{Ethics approval and consent to participate}

The Human Research Ethics Committee (Medical) at Wits (M181050) and other relevant authorities approved this study. Participants gave written consent for participation and recording of the workshop.

\section{Consent for publication}

Not applicable

\section{Availability of data and materials}

The raw data (including the audio recordings) supporting the results have been stored securely by the corresponding author, under password protection, in a locked cupboard after completion of the study. This research was done in partial fulfilment of a Master of Medicine degree and therefore the rich pictures were made available to the Post Graduate Studies department at Wits.

\section{Competing interests}

The authors declare that they have no financial or personal relationships which may have inappropriately influenced us in writing this paper.

\section{Funding}

The Department of Anaesthesiology bore the cost of printing and paper for the proposal, ethics, post graduate approvals and the continuous professional development point applications. Light refreshments during the workshop were paid for by the corresponding author (MK). The pens and paper used to draw the rich pictures were supplied by the author (JS). 


\section{Authors contributions}

Concept and design: MK, JS, HP, LGT

Data collection: MK, JS

Data analysis: MK, JS, HP, LGT

Drafting of article: MK, JS, HP, LGT

Final approval of the version to be published: MK, JS, HP, LGT

\section{Acknowledgments}

This research was done in partial fulfilment of a Master of Medicine degree.

The authors would like to thank Dr Paul Abrahams, for his kind contribution and assistance with the workshop.

\section{Authors information}

Author, MK, is a senior registrar in the Wits academic circuit where the study was completed.

Authors, JS, HP and LGT were supervisors for the study as part of Post Graduate Studies.

Authors MK, JS and HP- Department of Anaesthesiology, School of Clinical Medicine, Faculty of Health Sciences, University of the Witwatersrand, Johannesburg, South Africa.

Author LGT- Dean: Faculty of Health Sciences, University of Cape Town, Cape Town, South Africa

\section{References}

1. National Department of Health. 2030 Human Resources for Health Strategy: Investing in the health workforce for Universal Health Coverage. Pretoria: Government Printers, 2020.

2. Kwenin DO, Muathe S, Nzulwa R. The influence of employee rewards, human resource policies and job satisfaction on the retention of employees in Vodafone Ghana Limited. EJBM. 2013;5(12):13-20. doi:10.6007/IJARBSS/v3-i12/421

3. Herzberg F, Mausner B, Snyderman B. The Motivation to Work. Second New York, NY: John Wiley \& Sons; 1959.

4. The Society for Human Resource Management. Using recognition and other workplace efforts to engage employees: SHRM survey findings: SHRM; 2018. [Accessed on: 4 August 2018] Available 
from: https://shrm.org/hr-today/trends-and-forecasting/research-and- surveys/Documents/SHRMGloboforceEmployeeRecognition\%202018.pdf

5. Ongori H. A review of the literature on employee turnover. Afr J Bus 2007;1(3):49-54. doi:10.12691/ajphr-3-6-3

6. Hassan M, Hassan S, Khan KUD, Akramnaseem M. Employee retention as a challenge in leather industry. GJHSS. 2011 Mar;11(2):9-13.

7. Hom PW, Shaw JD, Lee TW, Hausknecht JP. One hundred years of employee turnover theory and research. J Appl Psychol. 2017 Mar;102(3):530-45. doi:10.1037/apl0000103

8. Glebbeek AC, Bax EH. Is high employee turnover really harmful? An emperical test using company records. Acad Manage J. 2004 Apr;47(2):277-86. https://doi.org/10.5465/20159578

9. Ntuli ST, Maboya E. Geographical distribution and profile of medical doctors in public sector hospitals of the Limpopo Province, South Africa. Afr J Prim Health Care Fam Med. 2017;9(1):1-5. doi:10.4102/phcfm.v9i1.1443

10. Health Market Inquiry: Competition Commission South Africa; September 2019. [Accessed on: 10 November ] Available from:http://www.compcom.co.za/wp-content/uploads/2014/09/HealthMarket-Inquiry-Report.pdf

11. Ashmore J. "Going private": a qualitative comparison of medical specialists' job satisfaction in the public and private sectors of South Africa. Hum Resour Health. 2013 Dec;11(1):1-12. doi:10.1186/1478-4491-11-1

12. Odhiambo J, Rwabukwisi FC, Rusangwa C, Rusanganwa V, Hirschhorn LR, Nahimana E, et al. Health worker attrition at a rural district hospital in Rwanda: A need for improved placement and retention strategies. Pan Afr Med J. 2017;27(1):1-7. doi:10.11604/pamj.2017.27.168.11943

13. Farham B. Migration of Health Professionals. The Lancet. 2005;366(9481):199. https://doi.org/10.1016/S0140-6736(므) $66897-3$

14. Scribante J. The development of a framework for improvement of intensive care delivery: A systemic intervention [Thesis]. Johannesburg, South Africa: University of the Witwatersrand;

15. Checkland P, Poulter J. Learning for action: A short definitive account of soft systems methodology, and its use for practitioners, teachers and students. Chichester, United Kingdom: Wiley;

16. Bell S, Morse S. Rich pictures: A means to explore the "sustainable mind"? Sust Dev. 2013;21:30-47. doi:10.1002/sd.497 
17. Braun V, Clarke V. Using thematic analysis in psychology. Qual Res Psychol. 2006;3:77-101. doi:10.1191/1478088706qp063oa

18. Kuijk A. Two Factor Theory by Frederick Herzberg Tools Hero: Tools Hero; 2018. [Accessed on: 1 August 2018] Available from: https://toolshero.com/psychology/theories-of-motivation/two-factortheory-herzberg/

19. Wildschut A. Doctors in the public service too few for too many. Human Sciences Research Council. [Accessed on: 30 January 2018] Available from: http://www.hsrc.ac.za/en/review/november-/publicservice-doctors

20. Samuel MO, Chipunza C. Employee retention and turnover: Using motivational variables as a panacea. Afr J Bus Manage. 2009;3(8):410-5. doi:10.5897/AJBM09.125

21. Oberoi SS, Lin V. Brain drain of doctors from southern Africa: Brain gain for Australia. Aust Health Rev. 2006;30(1):25-33. doi:10.1071/AH060025

22. Schoo A, Stagnitti K, Mercer C, Dunbar J. A conceptual model for recruitment and retention: Allied health workforce enhancement in Western Victoria, Australia. Rural Remote Health. 2005;5:477.

23. Lindfors PM, Meretoja OA, Toyry SM, Luukkonen RA, Elovainio MJ, Leino TJ. Job satisfaction, work ability and life satisfaction among Finnish anaesthesiologists. Acta Anaesthesiol Scand. 2007;51(7):815-22. doi:10.1111/j.1399-6576.2007.01343.x

24. Jack H, Canavan M, Ofori-Atta A, Taylor L, Bradley E. Recruitment and retention of mental health workers in Ghana. Plos one. 2013 Feb;8(2):e57940. https://doi.org/10.1371/journal.pone.0057940

25. Gupta-Sunderji M. Employee retention and turnover: The real reasons employees stay or go. Financial management institute journal. 2004;15(2):37-40.

\section{Figures}




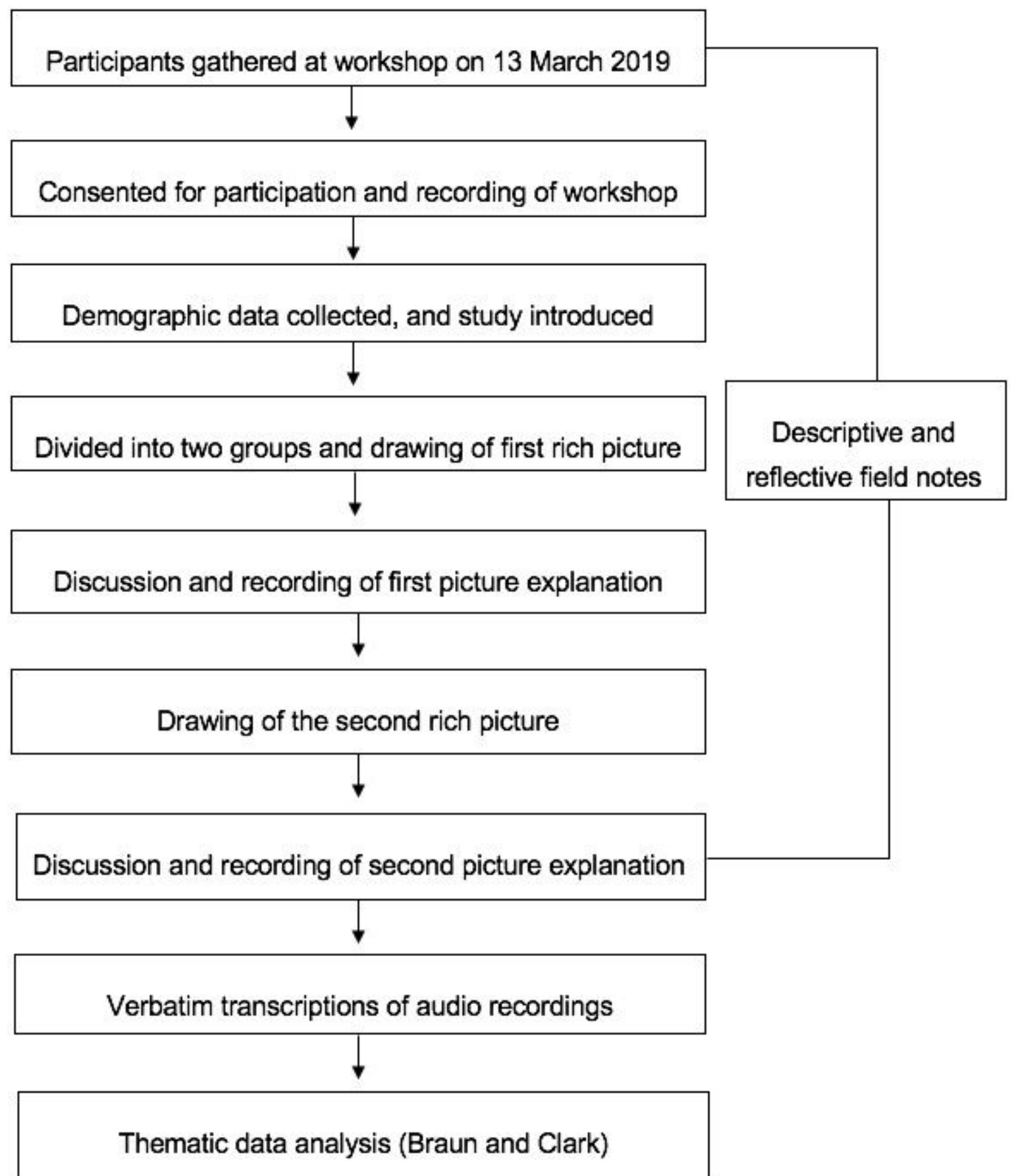

Figure 1

Sequence of events of data collection and analysis 


\section{Job dissatisfaction}

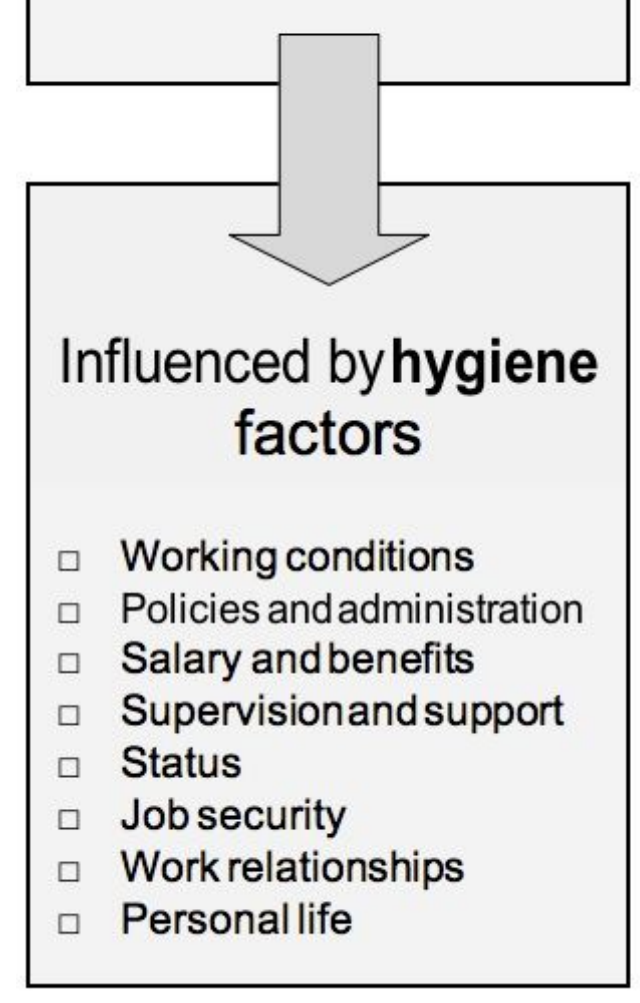

\section{Job satisfaction}

Improving the satisfier (motivator) factors increases job satisfaction
Improving the hygiene factors decreases job dissatisfaction
Recognition

ㅁ Achievement

- Advancement

․ Professional growth

- Responsibility

$\square$ Job challenge

Figure 2

Herzberg's Motivation-Hygiene Theory

\section{Supplementary Files}

This is a list of supplementary files associated with this preprint. Click to download.

- supplement1.pdf

- supplement2.pdf

- supplement3.pdf

- supplement4.pdf 